\title{
Idiopathic Segmental Infarction of the Greater Omentum
}

\author{
Col AS Sandhu*, Maj Gen P Rao (Retd) ${ }^{+}$, Col S Arora" \\ MJAFI 2009; 65 : 67-68
}

Key Words : Omental infarction; Acute abdomen

\section{Introduction}

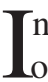
nfarction of the greater omentum is an unusual cause of acute abdomen. Accurate clinical diagnosis is rare since the condition usually mimics acute appendicitis or cholecystitis. This case report highlights the clinical features and management of this infrequently encountered condition.

\section{Case Report}

A previously healthy 25 -year old airman presented with the history of mild to moderate pain in the right lower abdomen of 3 days duration. Pain was severe since past 8 hours. There was no history of shift of pain, nausea, vomiting, anorexia, loose motions or trauma. General examination was normal but for low grade fever and tachycardia. Patient was not obese. There was tenderness, guarding and rebound tenderness in right iliac fossa. There was no lump. Systemic examination was normal. Investigations revealed polymorphonuclear leucocytosis. A provisional diagnosis of acute appendicitis was made and patient prepared for emergency appendectomy. Since a clinical diagnosis of acute appendicitis was made and there was no palpable lump in the right iliac fossa imaging in the form of abdominal ultrasonography was not done.

The abdomen was opened by Lanz incision. There was a moderate amount of serosanguineous peritoneal fluid. There was a $5 \times 5 \times 4 \mathrm{~cm}$ bluish-black hemorrhagic omental mass in the right iliac fossa (Fig 1). There was no omental torsion. Appendix, caecum, terminal ileum and mesentery were normal. The omental mass was excised and appendectomy performed. Post-operative recovery was uneventful.

Microscopic examination of the omental mass showed venous congestion, hemorrhagic infarction, fat necrosis and polymorphonuclear cell infiltration. There was no granuloma formation or vasculitis. Appendix was normal.

\section{Discussion}

Bush first described idiopathic omental infarction in 1896 [1]. Over 250 cases have been reported in the literature [2]. No single theory adequately explains all cases of omental infarction [3]. Occult trauma has been suggested. Increased abdominal pressure from coughing, sneezing, laughing or Valsalva's maneuver or engorgement of dependent omental veins after a heavy meal resulting in venous extravasation and subsequent thrombosis has been postulated. Gravitational pull of fat laden omentum of obese individuals on thin walled omental veins has also been hypothesized. A developmental abnormality has also been suggested. The right lateral border of the greater omentum may have a tenuous blood supply and thus be susceptible to infarction. It has been suggested that in the obese, the omentum could outgrow its blood supply and thus undergo infarction. Compression of greater omentum between an enlarged liver and abdominal wall could also be a cause. Secondary omental infarction results from omental torsion.

Omental infarction is most common in obese males in their fifties [4] though cases in childhood have been reported [5]. The index case is unusual in that the patient was young and non-obese. The condition commonly mimics acute appendicitis, cholecystitis [3] or diverticulitis [6]. Segmental omental infarction should be considered in the differential diagnosis of acute abdomen especially when the presentation is atypical

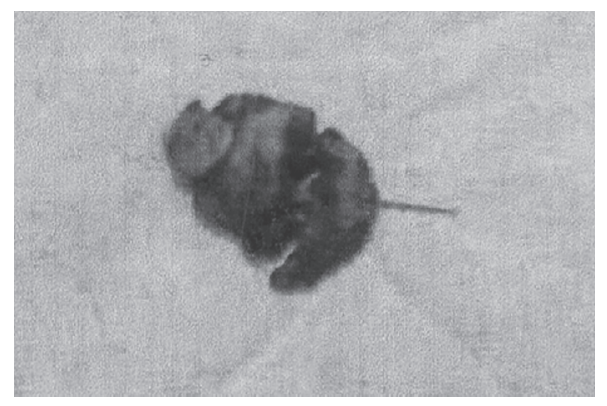

Fig. 1 : Excised omental mass

"Senior Advisor (Surgery \& Urology), Command Hospital (Southern Command), Pune- 411 040. ${ }^{+}$Prof \& Head (Department of Surgery) Rural Institute of Medical Science \& Research, Saifai, Dist: Etawah, UP- 206 301. \# Senior Advisor (Pathology), 155 Base Hospital, C/o 99 APO.

Received : 11.03.08; Accepted : 29.08.08 E-mail: arjunssandhu@gmail.com 
and all other causes have been excluded [7]. Sonographic and computed tomographic (CT) diagnosis has been described [4]. Unenhanced CT features of omental infarction consist of a heterogeneous density fatty mass containing hyperattenuating streaks located in the greater omentum between the anterior abdominal wall and the colon. Free peritoneal fluid may also be seen [6]. A classic finding at laparotomy is sanguineous/ serosanguineous peritoneal fluid which was also seen in our case. The diagnosis usually goes unsuspected until normal appendix, small intestine, caecum, mesentery, colon and biliary tract are noted. Infarction nearly always involves the right lateral dependent free edge of greater omentum. Excision of affected omentum is curative though Goh et al [7], have described non-operative management in a case which was successfully diagnosed by CT. Surgical excision prevents adhesion formation and septic complications. Laparoscopic management has recently been reported by several workers and is emerging as the treatment of choice $[3,5,8,10]$.

\section{Conflicts of Interest}

None identified

\section{References}

1. Rich RH, Filler RM. Segmental infarction of the greater omentum- a cause of acute abdomen in childhood. Can J Surg 1983; 26: 241 .

2. Quinn AD, Jothi RK. Idiopathic segmental infarction of the greater omentum- report of a case mimicking appendicitis.
Postgrad Med 1986; 79: 133.

3. Perez Saborido B, Jimenez Romero C, Marquez Medina E, Gimeno Calvo A, et al. Idiopathic Segmental Infarction of the greater omentum as a cause of acute abdomen- report of two cases and review of the literature. Hepatogastroenterology 2001; 48: 737-40.

4. Paroz A, Halkic N, Pezzetta E, Martinet O. Idiopathic segmental infarction of the greater omentum: a rare cause of acute abdomen. J Gastrointest Surg 2003; 7:805-8.

5. Sakellaris G, Stathopoulos E, Kafousi M, Arbiros J, Bitsori M, Charissis G. Primary idiopathic segmental infarction of the greater omentum: two cases of acute abdomen in childhood. J Pediatr Surg 2004; 39:1264-6.

6. Cianci R, Filippone A, Basilico R, Storto ML. Idiopathic segmental infarction of the greater omentum diagnosed by unenhanced multidetector-row CT and treated successfully by laparoscopy. Emerg Radiol 2007; 3: [Epub ahead of print].

7. Safioleas M, Stametakos M, Giaslakiotis K, Smirnis A, Safioleas P. Acute abdomen due to primary omentitis- a case report. Int Semin Surg Oncol. 2007; 26:19.

8. Van Waes O, Van der Elst M, Stassen L, Tjebbes F. Laparoscopic diagnosis and treatment of idiopathic segmental infarction of the greater omentum. Case report. Surg Endosc 2001; 15:1226.

9. Goh BK, Koong HN. Non-operative management of idiopathic segmental infarction of the greater omentum successfully diagnosed by computed tomography. J Gastroenterol Hepatol 2006; 21:1638-9.

10. Kerem M, Bedirli A, Mentes BB, Sakrak O, Pala I, Oguz M. Torsion of the greater omentum: preoperative computed tomographic diagnosis and therapeutic laparoscopy. JSLS 2005; 9:494-6. 